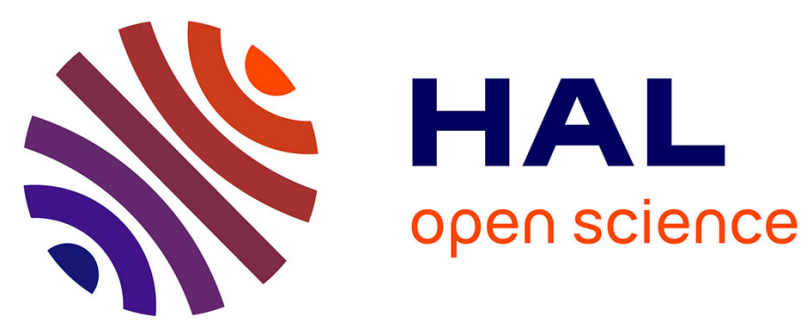

\title{
Narrative and deliberative instauration: The use of narrative as process and artefact in the social construction of institutions
}

\author{
William James Fear, Ricardo Azambuja
}

\section{- To cite this version:}

William James Fear, Ricardo Azambuja. Narrative and deliberative instauration: The use of narrative as process and artefact in the social construction of institutions. Learning, Culture and Social Interaction, 2014, 3 (4), pp.286-295. 10.1016/j.lcsi.2014.04.002 . hal-00991744

\section{HAL Id: hal-00991744 \\ http://hal.grenoble-em.com/hal-00991744}

Submitted on 12 Jun 2014

HAL is a multi-disciplinary open access archive for the deposit and dissemination of scientific research documents, whether they are published or not. The documents may come from teaching and research institutions in France or abroad, or from public or private research centers.
L'archive ouverte pluridisciplinaire HAL, est destinée au dépôt et à la diffusion de documents scientifiques de niveau recherche, publiés ou non, émanant des établissements d'enseignement et de recherche français ou étrangers, des laboratoires publics ou privés. 
Title: Narrative and deliberative instauration: The use of narrative as process and artefact in the social construction of institutions

NOTICE: this is the author's version of a work that was accepted for publication in Learning, Culture and Social Interaction. Changes resulting from the publishing process, such as peer review, editing, corrections, structural formatting, and other quality control mechanisms may not be reflected in this document. Changes may have been made to this work since it was submitted for publication. A definitive version was subsequently published in Learning, Culture and Social Interaction. Online publication complete: 14-MAY-2014

Please cite as

Fear, WJ and Azambuja, R (2014). Narrative and deliberative instauration: The use of narrative as process and artefact in the social construction of institutions. Learning, Culture and Social Interaction. Online publication complete: 14-MAY-2014. DOI information: 10.1016/j.lcsi.2014.04.002

Author 1: William James Fear (ChPsychol)

Department of Organizational Psychology

Birkbeck College University of London

Malet Street

London

Email: w.fear@bbk.ac.uk

Author 2: Ricardo Azambuja

Affiliate Professor

Grenoble École de Management, France

ricardo.azambuja@essec.edu

Corresponding Author: William James Fear (ChPsychol)

Department of Organizational Psychology

Birkbeck College University of London

Malet Street

London

Email: w.fear@bbk.ac.uk

Tel: +447891469869 


\begin{abstract}
Patient Safety is a global institution in the field largely assumed to have emerged following the publication of To Err Is Human by the Institute of Medicine in 1999. In this paper we demonstrate the Patient Safety has been constructed as an institution separately in the practice of anaesthesia since 1954 and in hospitalised care since 1964. The publication of To Err was, in fact, only one of a number of later field configuring events. We use Bruner's (1991) theory of narrative to frame the institution building process which we term deliberative instauration in recognition of the historic literature on the subject. We further link the process of institution building to Vygotsky's theory of social mediation and the use of artefacts in relation to the object of intended action. We conclude that a narrative can be understood as both an artefact and a process used in the social construction of institutions by professional psychological collectives (in this case physicians).
\end{abstract}

\title{
Key words
}

Institution, artefact, narrative, patient safety, healthcare 


\section{Introduction}

Collective, homogenous patterns of behaviour of individuals are the product of stable networks of relations. These stable and homogenous patterns of behaviour become sanctioned by the members of the psychological collective to forms institutions (e.g., see, Daniels, 2010, 2012, Undated; DiMaggio \& Powell, 1991; Scott, 2007). Institutions are complex modifications of original mediated responses between individuals and objects and one of the resulting behaviours is the development, maintenance, and transformation of those same institutions. However, institutions are also complex social constructions in a state of constant flux that both enable and constrain the behaviours of the members. The institutions are subject to change and transformation through the actions of their members. The assumption that institutions have a normative effect on behaviour is contradicted by changes made to the institution/s by the members; this is the paradox of institutions. In keeping with this the generation of alternatives to existing routine practices, the transformation of existing institutions, and the building of new institutions, are generally considered phenomena that are worthy of study as special forms of action.

Theories of objectification of norms of action and cognitions into artefacts that decisively influence the course of action can be found in philosophy (e.g., Dewey, 1938/1991), the social sciences (e.g., Latour, 1991, 1992), and psychology (e.g., Vygotsky, 1979). The interaction between the human agent and its object is mediated by tools and signs; artefacts. The meanings associated with artefacts are internalized through participating in common activities with other humans. Equally, the shared creation of artefacts is a means, by default and/or by design, of reflecting and of transforming activity, and as such is a key to changing practices (Vygotsky, 1986). The same basic mediational means, cultural artefacts, are used on the individual and social planes (Vygotsky, 1987), calling into question the boundary between social and individual. Simply put, the creation and use of artefacts is an institutional process that not only institutionalizes the web of behaviours, cognitions, beliefs, meanings and so on in which the artefact is embedded but also one that builds and transforms institutions.

In this paper we address the question of the complex social process of changing, or transforming, the routine practice of a psychological collective over a long period of time on a global scale. That is, we are concerned with the knowing transformation, or construction, of a social institution (deliberative instauration; Kantor, 1929). The social institution in question is Patient Safety and we take account of developments between circa 1954 and circa 1994. We consider two cases: Anaesthesia (1954-1985); and hospitalised care (1964-1994). In both cases the pattern of activity is the same and takes place on a global scale. Taking a social constructionist approach we analyse the discourses of the relevant profession, as they are themselves constitutive of cultural life. They make distinctions, furnish rationales for action, and implicitly, and explicitly, evaluate forms of conduct (Gergen, 1996). Discourse is a form of participating in common activities with other humans and the inscription of discourse (in text) is the shared creation of artefacts, especially within a profession. We expand the understanding of the role of artefacts and the process of engaging with artefacts using Bruner's (1991) theory of narrative.

In taking a social constructionist perspective we consider that traditional empirical research - the observation of objects and events - is most effectively deployed in illustrating interesting or challenging ideas, tracing patterns of conduct of major significance to the society, and generating debate and dialogue (Gergen, 1985, 1996). This is to say we are neither setting out to test theory nor, necessarily, to develop theory per se. We are using theory to frame our observations. The contribution made by this paper is to trace a pattern of 
conduct of major significance to society and to show how the observed process can generate substantial lasting changes in individual and collective routine behaviour.

The rest of this paper is structured as follows. First we provide some brief context for Patient Safety since 1999. We do this because this context is the most often referred to understanding of the institution and industry. We then discuss the relevant theory of narrative and text followed by an overview of the method. Next we present the case studies of anaesthesia and hospitalised care separately, focussing on the breach of the canonical script and the reconstitution of the canonical script. We then provide a discussion of the process of deliberative instauration, the role of narrative and the use of texts. We end with a short summary conclusion.

With regard to reflexivity we have little to say that has not already been said and articulated in the literature relating to social constructionism. Clearly we aware that the production of an academic paper is a shared process during which an artefact (the article) is produced in keeping with the institutional and cultural norms of the psychological collective and according to the conventions of the selected genre. The concern that the observation of a narrative process at work in wider society may be a practice of sensemaking on the part of the observer applies equally to any observation, and, indeed, we would argue that this is inevitably the case.

\section{The context of Patient Safety}

Patient Safety is a global institution in the healthcare industry. Typically Patient Safety is considered post-1999 following the publication of To Err is Human (To Err hereafter; Kohn, Corrigan, and Donaldson, 1999) by The Institute of Medicine (IOM). The publication of To Err had a substantive impact on the American public, policy makers, and medical establishment which went on to ripple around the world. Following its publication there was an increase in available funding to support patient safety research, with a matching increase in subject-related publications, a growth in the number of organizations, changes in policy, regulation, legislation and accreditation world-wide, and a general change and growth in related practices, beliefs, and rules, and the network of related organizations within healthcare.

However, at the time of publication of To Err, Patient Safety was already well established globally not only in Anesthesia but at the level of the hospitalised care also, and a number of voluntary error reporting systems and organizations were already in place, and had been for substantial periods of time. This paper considers the events leading up to the apparent impact of To Err rather than supporting the assumption that the publication of To Err was the key event (while recognising that it was a key event). The publication of To Err is best conceptualised as one of a series of field configuring events (Anand \& Watson, 2004; Hardy \& Maguire, 2010; Lampel \& Meyer, 2008) in a sequence of field configuring events spanning roughly seven years (see below).

While there is no doubt about the level of institutional development following the series of field configuring events and the publication of To Err, there is equally no evidence of a substantive change in either safety or quality in hospitalised care at either an equivalent level or scale. Indeed, some of the principal actors in the process of institution building, Luciane Leape and Don Berwick among them, openly recognise that Patient Safety has not led to improvements in either safety or quality of care (e.g. Jha, Prasopa-Plaizier \& Larizgoitia et. al., 2010; Leape, Berwick \& Clancy, et. al., 2009; Woodward, Mytton \& Lemer et. al., 2010).

Of equal importance is the recognition, in the case of anesthesia, that reported mortality rates may have decreased but this is due to the adoption of improved technology, or 
technological artefacts, not as a consequence of changes at the institutional level (Gaba, 2000). Similarly, technical changes in interventions used in hospitalised care that lead to improved outcomes linked directly to that technical change are often adopted as outcomes of institutional change. This is acknowledged as coherence by contemporaneity: the belief that things happening at the same time must be connected (Bruner, 1991). What we see in a recent report (Making Health Care Safer II, 2013), 14 years after the publication of To Err, is that of 100 patient safety interventions reviewed only 10 had sufficient evidence of effectiveness and implementation to be "strongly encouraged" for adoption. And, again, these were discrete technical processes relating to modifications and changes in equally discrete and already existing practices.

While there is a point of interest here with regard to the development of artefacts within the institution, and the subsequent role of those artefacts within the institution, this is a different level of detail to that with which we are concerned in this paper. Equally, the point is made that one of the outcomes of the reification of the institution is the institutionalization of the attendant behavioural norms associated with the institution. These behavioural norms include meanings, beliefs, cognitions, and behaviours such as the belief that the reification of the institution has resulted in the desired outcomes. Put more simply, the social construction of an institution may change various modes of behaviour in specific modalities but it does not necessarily result in a change in outcomes in the natural world even though it does result in a change in outcome in the socially constructed world/s we inhabit.

To be sure, To Err remains an important and potent artefact. But, to use an analogy, the publication of To Err was similar to the placement of a latest model of an expensive sports car in an equally expensive and well known car showroom with a concurrent substantial advertising campaign. What follows is a series of strong sales of the car. What we are interested in is the mundane and protracted process of designing and building the prototype model of the car and getting it to market.

\section{Narrative}

Narrative is recognised as a means by which professional occupations bring about institutional change (Czarniawska, 1997, 1998, 2009; Greenwood, Suddaby \& Hinings, 2002; Hardy \& Maguire, 2010; Hardy \& Phillips, 2004; Lawrence \& Suddaby, 2006; Pentland, 1999). This understanding includes the use of narratives in the construction of institutions as cultural objects through collective action (Czarniawska, 2009; Kantor, 1929; Shanahan, Jones \& McBeth, 2011)

Narrative is both the means whereby human beings organize their understanding of reality (Bruner, 1991). Narratives are both located in, and leave traces in, texts. Particularly written texts in literate societies (Barthes, 1977; Czarniawska, 2004; Latour, 2005; Olson, 1994; Ricoeur, 1971; White, 1981). The use of narratives inscribed in language-based texts as the means to build and transform institutions defines narrative as an artefact (Vygotsky, 1978; Wartofsky, 1973; Wertsch, 1998). That is, sets of rules, norms, and beliefs can be inscribed in the form of a narrative, or set of narratives (an accrual; Bruner, 1991), in texts to promote and legitimate cooperative activity. Inscribing the accrued narrative/s in text would similarly build, or create or transform, institutions (Phillips, Lawrence and Hardy, 2004).

Following Bruner (1991) narratives are a version of reality governed by convention and narrative necessity rather than by empirical verification and logical requiredness. The representational value, the verisimilitude, is judged on the basis of the fidelity and coherence of the narrative (Fisher, 1984, 1985). They accrue over time to bring about traditions and cultures and establish lasting behaviours in social systems. Once shared culturally narrative 
accruals achieve collective representation, exteriority, and the power of constraint.

Narratives, in their accrual, construct a history and a tradition that permits a continuity into the present. There is a perpetual construction and reconstruction of the past that provides canonicity.

As narratives are accrued they act as warrants to legitimise particular beliefs and attendant behaviours (Fisher, 1985; Gergen, 1985). They cannot be incorporated in their entirety otherwise the structured narrative (Bartel \& Garud, 2009) would be unwieldy, cumbersome, and clumsy and would lose the necessary aesthetic required of any contextually legitimate object (Lind, 1980). Thus we must expect that accrued narratives are summarised into warrants through some form of symbolic representation that refers back to the original accrued narrative in its entirety.

Of interest is how narrative 'operates as an instrument of mind in the construction of reality' (Bruner, 1991; p. 6). Bruner gives 10 features of narrative in respect of this and here we focus on those parts we have been able to identify in the process of institution building. This is not to say the other parts cannot be, or have not been identified. But the purpose of this paper is to use the theory to frame our observations, not to test the theory. Our observations identified a repeating pattern of global significance within a particular setting. What the theory does is provide a means of interpreting and understanding those observations. In this sense the theory is a cultural tool which we use to reconstruct a version of social reality according to institutional conventions.

The starting point in the process is the violation of an existing, implicit canonical script in such a manner as to do violence to the legitimacy of the canonical script. This requires a precipitating event that leads people to see the taken for granted socially constructed reality in a fresh way. This breach can be created either through linguistic means (as in the case of hospitalised care) or through the use of a 'putatively deligitimising precipitating event in the plot' (p. 12). This is the first reasonably identifiable point at which we can assume a recorded level of disruption to the existing institution. It is the 'beginning' of the narrative as a process. We acknowledge here also that in keeping with our above comment the existing institution's narrative is breached by a narrative.

The 'ending' is the point at which we can reasonably assume that a new normative pattern of conduct has been established. The institution has been reconstituted. This is a point at which narrative accrual reaches a critical mass such that a new canon is established; a new culture, tradition and history with the power of constraint. We have termed the establishment of the new canon 'consolidation' as it emerges, we propose, at the cessation of accrual of further narratives, noting that this does not preclude the repetition of accrued narratives in future, repeated, versions of the canon.

To conclude, on the one hand, narratives are in and of themselves an artefact, a cultural tool, a prosthetic device. On the other hand narrative is a process of social construction, a form of constituting reality; of the building of history, traditions, cultures, and institutions. Thus the tool, the artefact, is mirrored in the process of using that artefact. This understanding has been similarly explored by others such as, for example, and in no particular order, Wartofsky (1987) in relation to artefacts, Knorr-Cetina (1997) in relation to epistemic objects, Dewey (1938) in philosophy, Vygotsky (1981) in relation to culture, Woods (1998) in relation to cognitive science, and Engeström and colleagues in relation to written texts (Engeström, Brown, Engeström and Koistinen, 1990).

\section{Text}


Some discussion of text is appropriate given our study was a cultural-historical analysis of the artefacts of a culture. It was an analysis of objects the inscribed with the discourse of that culture in relation to a particular institution.

A text is defined as a body, or collection, of signs, or traces of events, inscribed on a permanent medium that can be read to infer and extract meaning (Barthes, 1977; Olson, 1994; Ricoeur, 1971). Written texts are used to build (or create or transform) institutions (Kantor, 1929; Lawrence \& Suddaby, 2006; Phillips, Lawrence \& Hardy, 2004), and make the narrative available for further use through translation (Wertsch, 1998).

Texts are not only instauration objects (i.e. they are tools used to build institutions; they are artefacts), they also carry traces of the existing culture, events, and actions of individuals (Barthes, 1977; Kerosuo, Kajamaa \& Engeström, 2006; Latour, 2005; Olson, 1994; Ricoeur, 1971; White, 1981). We can reasonably expect to be able to reconstruct patterns of behaviour from the traces left in texts, including written texts, regardless of the intentions of author/s.

We can draw conclusions about past activities by studying material traces (Kerosuo et. al., 2006; Schiffer, 1999). The inscription/transcription of narrative in/into a text creates a material social artefact (Gergen, 1985), a cultural tool that facilitates engagement with the cultural prerequisites for functioning in the contextualised group (including wider society; Vygotsky, 1978). Artefacts are amenable to scrutiny as objects whatever form they take, including cognitive artefacts (Norman, 1991).

We studied the artefacts, the texts, of the psychological collective of physicians, and related collectives. We were able to identify the process of deliberative instauration from the traces in the texts. That is, both the events and other texts (objects) left traces from which a distinct pattern could be reconstructed (Parker, 1994). These traces accumulate to become further discourses, including narratives patterns (Ricoeur, 1981).

For example, field configuring events are well recognised and documented in the literature on organizational institution building (Hardy \& Maguire, 2010; Lampel \& Meyer, 2008), and the field configuring events for the institution of Patient Safety in both anaesthesia and healthcare have left strong traces in both the formal texts of the collectives and in less formal texts such as websites and the grey literature.

\section{Method}

We took a social constructionist perspective (Gergen, 1985, 1996) to the project in keeping with the understanding that institutions are themselves social constructions - whether occurring as a consequence of either contingently constrained behaviour or as a consequence of deliberate activity. We analysed a corpus of texts from an existing archive and considered the texts as both data sources and artefacts in their own right (Schiffer, 1999). We had three bodies of texts. One was a set of texts written by and for members of the psychological collective. These were drawn from the professional journals of the collective (e.g. The New England Journal of Medicine, The Journal of the American Medical Association, The Annals of Surgery). In the practice of medicine academic texts are equally read by practitioners and there is little distinction between academics and practitioners and their journals. Thus academic texts become powerful artefacts within the community. Next was a body of texts used to influence the wider context (such as the APSF website and the report To Err). Finally there was a body of texts that both provided a historical and contemporary context and reviewed and critiqued Patient Safety. These texts were drawn both from the journals of the relevant collectives and from the wider literature. Further detail is provided below. 
The process of analysis and of identifying the breach and the reconstitution were far from straightforward, although it now seems relatively simple. We have given a summary of the process and attempted to highlight some of the key points. Further detail can be found in (disclosive reference). Importantly, we maintained a process of constant questioning and reference to the theory. Every observation and conclusion made by one author was cross referenced to the contextual literature and the theory by the other author. Thus we had what we might call an iterative auditing process (Stevenson \& Greenberg, 1998) that involved both authors, the theoretical frames, and the wider literature.

Consider, for example, that the role of the media has been posited as causal in the expansion of Patient Safety from Hospitalised Care into Healthcare. However, the literature tells us that the media were reporting the same observations of preventable injury and problems with hospitalised care in the 1800's. Similarly, Medical Malpratice Litigation has been posited as a driver for change, yet levels of litigation have not decreased (although they have in Anesthesia) and, indeed, the means to resolve the problem of MML was known and practiced in the 1970s and recommended by the Harvard Studies in 1984 (Brennan, Leape \& Laird, et. al., 1991; Leape, Brennan \& Laird, et. al., 1991).

\section{Dataset}

The data set was a corpus of texts drawn from an archive collated from a range of literatures that included medicine, psychology, social sciences, and grey literatures. Work on this archive is on-going and iterative and includes methods based on systematic reviewing and snowballing references from selected texts.

We selected three corpuses from the archive based on: 1) the identification of the initial breach of the canon; 2) the final consolidation and reification of the institution; and 3) the historical and contemporary comparative context.

We were able to identify the breach of the canon by following up references and finding a point at which the existing canon was overtly challenged; ie. breached in the literature of the collective by the identification of a previously unacknowledged human plight. The breach was confirmed by a recognised change in the behaviour of the collective as recorded in the literature of the collective.

The consolidation and reification of the institution is, by contrast, fairly easy to spot as the events have characteristic markers that are well documented in the literature (e.g., Hardy \& Maguire, 2010). These include particular forms of conferences and meetings, the setting up of regulatory bodies, the forming of associations, deliberate high levels of visibility, the involvement of government (at least at national level), and so on. Similarly the texts produced for reification are quite distinct and recognisable as they tend towards high level policy documents and contain foundational statements for institutional behaviours.

The analytical corpus for Anesthesia included three key texts-as-artefacts. The canon was breached by Beecher and Todd (1954), and the new canon consolidated with the publications of Cooper, Newbower, and Long et. al. (1978) and Cooper, Newbower and Kitz, (1984). The consolidation and reification of the institution and field configuring event is well documented by the Anaesthesia Patient Safety Foundation (1985) which was established by members of the Harvard medical fraternity.

The analytical corpus for hospitalised care includes five key texts. The canon was breached by Schimmel (1964) and the institution consolidated with the publications of Leape and colleagues (Brennan, Leape \& Laird, et al., 1991; Leape, 1994; Leape, Brennan \& Laird, et al., 1991) and the text by Bogner (1994), which was one of the outlets for Leape's (1994) 
seminal publication. The field configuring event culminates with the establishment of the National Patient Safety Foundation (1995) by members of the Harvard medical fraternity.

The analytical corpus for historical and contemporary comparative context included a wider range of texts. A number of authors have summarised different aspects of the context (the behavioural interactions, the setting, and so on) to the institution of Patient Safety, in both Anesthesia and hospitalised care. This matrix contains discourses and associated institutions of the hospital (e.g. Dranove, Durkac \& Shanley, 1996; Ermann \& Gabel, 1984; Fissell, 1992; Lewis \& Alexander, 1986), the nature of medical practice (Harris , 1977; Hunter, 1991), personal injury (Guarnieri, 1992), religious perfectionism, the sanctity of human life, the mass media (e.g, Millenson, 2002), medical malpractice litigation (e.g., Mohr, 2000), scientific exploration in medicine (Hunter, 1991), and Harvard Medical School (Haddon, 1980; Runyan, 2003).

The three corpuses overlap in relation to the historical and contemporary comparative context. Iterative reference to the corpus for historical and contemporary comparative context provided a means of questioning and challenging the developing assumptions and understandings as the work progressed.

\section{Analysis}

Although we explain the process for identifying relevant texts - artefacts - and the importance of the contents of those texts we caution the reader against assuming this is a straightforward process. With experience it becomes so but we spent substantial time developing an in-depth understanding of the nature of the 'textual world', identifying relevant texts, and becoming familiar with the context. We undertook a large amount of reading of a variety of documents and it took time to track down and unearth sources of texts and to follow up leads and references from the texts. We read and interpreted the selected texts in a number of ways. We read them as historical records, for their impact on the intended audience, and analysed them as artefacts identifying the use of warrants in the form of symbolic references. For example: the use of careful referencing in the texts to other texts; the use of particular statistical and other methods; the use of language and ways of presenting arguments, and so on.

We made use of the principles of the critical incident technique (CIT; Flanagan, 1954). We used the CIT as an exploratory (Bitner, Booms \& Tetreault 1990), and inductive method to observe an emergent pattern (Chell,1998). We identified: the authors of key texts and the events and/or observations made by those authors which led to the construction of the texts; responses, if any, to the key texts; the key constructs, arguments, and warrants used in those texts; the point in time at which those texts were published relative to the point in time of other related events and texts; key events that the literature recognises as important with the regard to the social construction of institutions (e.g., Phillips, Lawrence \& Hardy, 2004); and organizations associated with key events and texts. Consideration was given to the principles and techniques of both Foucauldian Discourse Analysis (FDA; Foucault, 1969/72; Kendall \& Wickham, 1999; Willig, 1990), and Critical Discourse Analysis (CDA; Fairclough, 2009; van Dijk, 1993). There was also an element of deconstruction of selected texts resulting in a set of related and ordered extracts of narratives.

This was an iterative process and not a linear one. We returned to the archive and wider literature, and especially to contextual literature, time and time again in order to find and validate traces of events and to confirm, or disconfirm, the importance of a particular text and the traces in that particular text. 
We found that 'the narrative', as an artefact, was identifiable through its consistent patterns and structures (Bruner, 1991; Fisher, 1985), including framing and anchoring elements and legitimacy stamps (warrants). In particular there are combinations of words and phrases (including numerical and statistical representations), and references to methods, techniques, approaches, that are repeated across contexts, settings, and situations, and which become accepted as facts (Jepperson, 1991).

\section{Cases}

\section{Anesthesia}

Beecher and Todd (1954) highlighted the high level of unnecessary deaths as a consequence of anesthesia. The paper violently challenged the implicit canonical script of the safety of Anaesthesia. The claim made by the canonical script that Anaesthesia was responsible for ' ... one death in 5000, in 10,000, in 15,000 cases,' is contrasted with the finding of 'one anesthesia death...in every 1560 anesthesias.' (p. 27). Beecher and Todd's publication was met with an equally violent response from their community.

Abajtan, Arrowood, Barret, \& Dwyer, et. al's (1955; the critique had 16 signatories) response states that Beecher and Todd's paper presents conclusions that are not justified, that the paper is a disservice to anaesthesiology and to the patient, and therefore should be publicly criticised, and that a distorted and completely misleading picture is presented. Nonetheless, following Beecher and Todd's publication there is a recognised problem with deaths related to, and as a direct consequence of, anaesthesia.

Publications on death rates tend to find an increasing number of attributable deaths until the 1970s and the publications by Cooper and colleagues (Cooper, Newbower and Long et. al., 2002/1978; Cooper, Newbower and Kitz, 1984), when reported deaths directly attributable to anaesthesia decline.

Cooper et. al. present a complex set of symbolic representations of accrued narratives. They recognise the problem (death or harm), and attribute cause (human error), 'Preventable mishaps resulting from human error contribute to anaesthetic risk. Human errors were believed to be a factor in $87 \%$ of 80 deaths attributable to anesthesia...' (p. 277), and provide solutions (e.g. better training and relief from sustained observation). The recognise that the current institution promotes human error and that the institution can be changed to reduce human error. They use a number of warrants such at the critical incident technique (Flanagan, 1954), which is linked to aviation safety. This overcomes the problem highlighted by Beecher and Todd for large amounts of data, which needed to be collected before the case went cold, and legitimates the way in which the data is used - to determine the process by which 'clearly preventable' errors occur. Other warrants include a body of published research in medical journals demonstrating the existence of the 'plight', which overcomes some of the criticisms levelled by Abajtan et. al., 'qualified analysis', categorization, classification and taxonomy of errors, and reference to human factors research; all now established warrants in medical approaches to preventing injury.

The importance of the work of Cooper and colleagues, and of Cooper in particular is acknowledged by the Anaesthesiology Patient Safety Foundation (APSF). The APSF was established in 1985 following a field configuring event, the International Symposium on the Prevention of Anesthesia Mortality and Morbidity, and the publication of a new canonical text (Eichhorn, Cooper \& Cullen, et. al., 1986).

By 1985 Patient Safety was an established global institution within the practice of Anaesthesia, and continues to be so. A key similarity of the texts presented at either end of 
the process (Beecher and Todd at the breach and Cooper et. al. at the reconstitution) is that they were based on intense original research that took place within, and involved members of, the community of interest. As such they were not only based on events of salience to the community but were actual events within the community.

\section{Hospitalised care}

The pattern in the case of hospitalised care is broadly consistent with the pattern observed in anesthesia. The initial breach of the canon occurred with a publication by Schimmel (2003/1964) which, similarly to Beecher and Todd, not highlights the number of deaths as a consequence of hospitalised care but explores the reasons and the context.

'It appears that the long hospital stay was the factor predisposing to the occurrence of adverse episodes...For whatever reason, the high incidence of untoward episodes was related to the length of stay in the hospital and thus reflects the general hazards of hospitalization.' (2003; p. 63).

Schimmel does caveat the observation noting that those most at risk and the elderly and the infirm and even more so when these two conditions are combined. Schimmel also notes that problems of adverse events occurring as a consequence of modern medicine and hospital procedures had been reported in medical journals since at least the 1950s.

In 1984 the Harvard Study was carried out under the auspices of Luciane Leape, MD in Harvard Medical School, in the state of New York and published in the New England Journal of Medicine in two parts in 1991 (Brennan, Leape \& Laird et. al., 1991; Leape, Brennan \& Laird et. al., 1991). The initial purpose was to address the medical malpractice crisis in US healthcare specifically in relation to hospitals in the state of New York, and a solution was indeed proposed but not implemented (Brennan, Leape \& Laird et. al., 1991).

The publications in 1991 expanded the scope of Patient Safety to cover hospitalised care, address the same concerns as articulated by Schimmel, and proposed '.... an agenda for research on quality of care' (Leape, Brennan \& Laird et. al., 1991; p. 383), and the need to attend to '...the systemic causes and consequences of errors, an effort that goes well beyond identifying culpable persons.' (p. 383).

Among other things, the authors recognised the need to address negligence in respect of the regulatory market-based institution of medical malpractice litigation (Brennan, Leape \& Laird et. al., 1991) and give consideration to the breach of the social contract of perfectionism (Blumenthal, 1994).

The narratives continue to accrue following the publication of the Harvard Study. Leape, Lawthers \& Brennan et. al. (1993) introduce the factors of management, complexity of care, errors, systems and programs of prevention. In 1994 (Leape, $1994 a, b$ ) the narratives are consolidated into a relatively standard paradigm. In particular, the publication Human Error in Medicine edited by Bogner (1994) is recognised as a creating a paradigm shift (Bates \& Gawande, 2000), although the book was already out of print by then (2000) indicating the relatively short lifespan of the material object but the continued development of the institution.

At this stage (c. 1994) in the history of Patient Safety in hospitalised care the narratives had accrued and there was a new canonical script and, to some extent, the field was stabilised. The organizations and institutions had been identified and established, and there was a substantive body of texts. However, as with anesthesia, there was still a requirement to 
establish an organization in order to reify the institution. This takes place using a field configuring event.

In October 1996 A conference titled Examining Errors In Health Care: Developing a Prevention, Education and Research Agenda was held at the Annenberg Centre for Health Sciences. The conference was organised by the American Medical Association (AMA) and the Joint Commission for the Accreditation of Healthcare Organizations (JCAHO) together with the American Association for the Advancement of Science and the Annenberg Foundation. At this meeting, the AMA announced the formation of the National Patient Safety Foundation (NPSF), and JCAHO announced that it was making its reporting system non-punitive. As with the field of Anesthesia the conference was a field configuring event that reified the institution in the form of an organization, the NPSF (now home to the Luciane Leape Institute). A large number of related texts were produced immediately following the foundation of the NPSF, including To Err in 1999.

A key similarity of the texts presented at either end of the process (Schimmel at the breach and Leape et. al. at the reconstitution) is that they were not based on intense original research that took place within, and involved members of, the community of interest. Schimmel's study was relatively small scale and did not involve direct reporting by members of the community and the Harvard Study was a commissioned evaluation that took place outside of hospital environment. Yet the Harvard Study is the basis of the empirical argument made for the institution of Patient Safety in hospitalised care from its first academic publication in 1991 through to the publication of To Err in 1999. The numerous theoretical warrants in To Err are drawn from Bogner's 1994 publication.

\section{Discussion}

In this paper deliberative instauration was theorized both in terms of individuals (actors) using narrative as an artefact, knowingly or unknowingly, and narrative as a process with which the actors are engaged. Individuals and collectives narrate and theorize change while at the same time using 'narrative texts' - narratives inscribed in language based texts - as artefacts. That is, individuals and collectives organize a set of rules, norms, and beliefs as a narrative and simultaneously employ narrative, or a set of narratives (an accrual), as a cultural tool to promote and legitimate cooperative activity. The pattern of activity becomes scripted, the script becomes canonical, and the canonical script becomes, in effect, the artefact that maintains the institution. For an institution is defined as a set of rules based normative activities and so on.

Two key events in the narrative process of institution building were identified: 1) The breach of the canonical script (Bruner, 1991; Fischer, 2003), a destabilising event in the field which disrupts the existing institution (i.e. breaches the canonical script), an occurrence of de-instauration; and 2) the later reconstitution of the canonical script, deliberative instauration, which stabilises the field and transforms or establishes the institution, following a period of narrative accrual (Bruner, 1991; Gergen, 1994).

As Bruner proposes, the breach of the canonical script allows for 'new' narratives to be shared as accruals. Narratives, in their accrual, construct a history and a tradition, even legitimacy, that permits a continuity into the present. There is a perpetual construction and reconstruction of the past that provides canonicity. The accrual of narratives allows us to work mentally in common to create a culture (acculturation; Kantor 1929; Gundry \& Rousseau, 1994), construct a history and tradition, and develop the legitimacy that continues into the present. Once shared culturally narrative accruals achieve collective representation, exteriority, and the power of constraint. 
Following the breach of the canonical script there is a period of readjustment temporally consistent with the size of the field. This ends when the necessary and sufficient narratives have accrued. The restoration of the canon is accompanied by the creation of a body (an object, an organization) to regulate the field relative to the new canonical script. It is at this point that the 'new' canonical script is institutionalized following a well-documented sequence of events usually referred to a field configuring events (sometimes in the singular).

It follows that stability cannot be restored to the field unless the field has been destabilised. It does not follow that the field will be (re)stabilised once it has been destabilised. It could equally be the case that the field disintegrates, fragments, shifts, and so on. What is also acknowledged is that narrative resolves the human plight, it does not solve it. In both of the cases presented here we find that while the human plight is resolved it is not solved. Indeed, that is the social power of narrative as an artefact - to provide meaning and purpose where perhaps there would otherwise be none.

Vygotsky (1978), stated that human activity has three fundamental characteristics. It is: 1) directed towards a material or ideal object; 2) mediated by artefacts (which may be concrete or abstract, and which includes language in all forms; Vygotsky, 1981); and 3) it is socially constituted within a culture. The means of mediation, the cultural tools and signs, are internalized during socialization by participating in common activities with other humans (Vygotsky, 1979). Clearly we need a way of explaining the internalization of the artefacts, especially when they are material object and we can explain this by, on the one hand, the attribution of meaning and on the other hand by the development of scripted, or routinized, patterns of behaviour. A scripted pattern of behaviour is, by the definition of narrative operationalised above, effectively a narrative. The shared creation of an artefact by default results in reflection and the practical transformation of activity (i.e. learning) and a change in practices (Vygotsky, 1986). Equally, the shared creation of a canonical script through narrative accrual changes practice and equally the establishment of a canonical script makes practice difficult to change. In terms of institutions the shared practice of creating an artefact is equivalent to institution building and the establishment of a canonical script is the equivalent to the establishment of an institution (see also Kantor, 1929 for a detailed revision of this process).

Artefacts are inscribed and encoded with intended patterns of use and the intended use is to influence the object (material or ideal) of activity (Vygotsky, 1978). Two forms of language, speaking and writing, are highlighted as powerful tools that both internalize and externalize psychological activity and construct and deconstruct knowledge (Swain \& Lapkin, 2002). The construction and deconstruction of knowledge and meaning are crucial processes in the building and transformation of institutions. Language is recognised as a key tool in this process and, furthermore, the purpose of institutions is to influence an object; that is, the role of institutions is to regulate behaviour in relation to an object.

In the final analysis institutions are repeated patterns of behaviour in relation to an object, and these institutions are part of the culture of the psychological collective. There can be no culture in the absence of institutions and institutions are meaningless in the absence of culture. In a sense, institutions are artefacts as they are abstract objects inscribed with intended patterns of use to influence another object of activity (e.g., see, Garud, Jain \& Kumaraswamy, 2002; Simon, 1976). Institutions also make use of artefacts. For example, large social institutions such as Patient Safety make use of legislation, professional practice guidelines, texts, organizations, beliefs, and so on.

The role played by narrative is equally two-fold. On the one hand we can observe a pattern of behaviour that repeats over time and which mimics that of a narrative from the breach of the canonical script through a process of narrative accrual to a reconstitution of a 
canonical script. On the other hand individuals and groups use narratives as tools to influence the object of activity. In the case presented here the narratives are inscribed as language in texts and the texts are themselves an artefact. The texts are a material representation of the abstract objects. That is, the texts represent both the tool with which the object is influenced and the object which is intended to be influenced (e.g. see Iedema, 2001; Prior, 2003; Wartofksy, 1973) .

These observations and the attendant theoretical frames present a challenge to the understanding of institutional entrepreneurship as commonly reported in the wider literature. The challenge is simply this. The activity of building and transforming institutions is clearly not the act of any one individual over time. The necessary and sufficient conditions and antecedents must be in place and the so-called institutional entrepreneur must act to take advantage of those conditions. Thus we see, for example, that in both cases presented here the canonical script was breached some time prior to the field configuring events that establish, i.e. reify, the institution in a wider setting. This deserves further consideration.

\section{Conclusion}

The introduction of a novel object imbued with meaning, an artefact, into a field has the potential to disrupt the field as it breaches the canonical script (a narrative form) that maintains the field. Stability is restored over time through the accrual of narratives that allows for a new canonical script to be developed and established. This process is one of institution building through shared activity and the use of cultural tools to influence the object of activity. The process of institution building both takes place within a culture and is a means of maintaining the culture of the psychological collective.

\section{References}

Abajtan Jr.,J., Arrowood, J.,G., Barret, R.,H., Dwyer, C.,S., Eversole, U.,H., Fine, J.,H., Hand, L.V ....Woodbridge, L.,V. (1955). Critique of "A Study of the Deaths Associated with Anesthesia and Surgery". Annals of Surgery, 142 (1), 138-141.

Anand, N. \& Watson, M. R. (2004). Tournament Rituals in the Evolution of Fields: The Case of the Grammy Awards. The Academy of Management Journal, 47 (1): 59-80

APSF. Anaesthesia Patient Safety Foundation (1985). www.apsf.org

Barthes, R. (1977). Image, music, text. Translated by Stephen Heath. London: Fontana Press.

Bartel C.A. and Garud R., (2009). The Role of Narratives in Sustaining Organizational Innovation. Organization Science, 20 (1), 107-117

Bates, D. W. and Gawande, A. A. (2000). Error in medicine: What have we learned? Annals of Intemal Medicine, 132, 9: 763-767

Beecher, H. K. and Todd, D. P. (1954). A Study of the deaths associated with anaesthesia and surgery. Annals of Surgery, 140, 1 2-34.

Blumenthal, D. (1994). Making medical errors into medical treasures. Journal of the American Medical Association, 272, 23: 1867-1868.

Bitner, M. J., Booms, B. H., \& Tetreault, M. S. (1990). The service encounter: Diagnosing favorable and unfavorable incidents. Journal of Marketing , 54(1), 71-84.

Bogner MS, ed. (1994). Human error in medicine. Hillsdale, NJ: L. Eribaum Associates,

Brennan, T A., Leape, L L., Laird, N M., Hebert, L., Localio, R., Lwthers, A. G., Newhouse, J. P., Weiler, P. C., and Hiatt, H. H. (1991). Incidence of adverse events and 
negligence in hospitalized patients: Results of the Harvard Medical Practice Study I. New England Journal of Medicine, 324:370-376.

Bruner, J. (1991). The narrative construction of reality. Critical Inquiry, 18, 1-21.

Chell, E. (1998). Critical incident technique. In G. Symon \& C. Cassell (Eds.), Qualitative methods and analysis in organizational research (pp. 51-72). London: Sage.

Cooper, J. B., Newbower, R. S., Long, C. D., and McPeek, B. (1978). Preventable anesthesia mishaps: A human factors study. Anesthesiology, 49:399-406. Republished in Quality and Safety in Healthcare, 2002, 11: 277-283.

Cooper, J. B., Newbower, R. S., and Kitz, R. J. (1984). An analysis of major errors and equipment failures in anesthesia management: Considerations for prevention and detection. Anesthesiology, 60: 34-42.

Czarniawska, B. (1997). Narrating the organization. Dramas of institutional identity. Chicago, IL : University of Chicago Press.

Czarniawska, B. (1998). A Narrative Approach in Organization Studies. Thousand Oaks, CA: Sage, 1998

Czarniawska, B. (2004). Narratives in social science research. London: Sage.

Czarniawska, B. (2009). Emerging Institutions: Pyramids or Anthills? Organization Studies, $30,423-441$

Daniels H. (2012) Institutional culture, social interaction and learning. Learning, Culture and Social Interaction, 1, 1: 2-11

Daniels, H. (2010) The mutual shaping of human action and institutional settings: a study of the transformation of children's services and professional work. The British Journal of Sociology of Education, 31, 4: 377-393

Daniels, H. (Undated). Institutions as historical products: analyzing communicative action as it brings about change. Retrieved September 2013 from www.cardiff.ac.uk/socsi/newsandevents/events/.../Harry\%20Daniels.doc

Dewey, J. (1938/1991) Logic, the theory of enquiry. The Later works of John Dewey, vol. 12, ed. Jo Ann Boydston. Carbondale and Edwardsville: Southern Illinois University Press.

DiMaggio, P. J., \& Powell, W. W. (1991). Introduction. In W. W. Powell \& P. J. DiMaggio (Eds.), The new institutionalism in organizational analysis, pp. 1-38. University of Chicago Press: Chicago.

Dranovek, D., Durkac, A. and Shanley, M., (1996). Are Multihospital Systems More Efficient? Health Affairs, (15), 1, 100-104

Eichhorn, J. H., Cooper, J. B., Cullen, D. J., Maier, W. R., Phillip, J. H. and Seeman, R. G. (1986). Standards for patient monitoring during anaesthesia at Harvard Medical School. Journal of the American Medical Association, 256, 8:1017-1020

Engeström, Y., Brown, K., Engeström, R., and Koistinen, K., (1990). Organizational forgetting: An activity theoretical perspective. In Collective remembering edited by D. Middleton and D. Edwards, 139-168. London, Newbury Park, New Delhi: Sage Publication.

Ermann, D. and Gabel, J. (1984). Multihospital systems: Issues and empirical findings. Health Affairs, 3 (1): 50-64

Fairclough, N. (2009). Critical discourse analysis: The critical study of language. Harlow, UK: Pearson Education.

Fear W.J., (2012). Discursive activity in the boardroom: The role of the minutes in the construction of social realities, Group and Organization Management, 37, 486-520.

Fisher, W.R., (1984). Narration as a human communication paradigm: The case of public moral argument. Communication Monographs, 51 1-22. 
Fisher, W. R. (1985). The narrative paradigm: An elaboration. Communication Monographs, 52: 347-367

Fischer, F. (2003). Reframing public policy: discursive politics and deliberative practices. Oxford University Press: Oxford.

Fissell, M. E. (1992). Readers, texts, and contexts: Vernacular medical works in early modern england. in R. Porter (ed.), The Popularization of Medicine, 1650-1850. London: Routledge. pp. 72-96.

Flanagan, J. C. (1954). The critical incident technique. Psychological Bulletin, 51:327-58.

Foucault, M. (1969/72). The archaeology of knowledge. London: Tavistock.

Gaba, D. M. (2000). Anaesthesiology as a model for patient safety in health care. British Medical Journal 320(7237); 785-788.

Garud, R. Jain, S. and Kumaraswamy, A. (2002). Institutional entrepreneurship in the sponsorship of common technological standards: The case of Sun Microsystems and Java. Academy of Management Journal, 45: 196-214.

Gergen, K. J. (1985). The social constructionist movement in modern psychology. American Psychologist, 40(3), 266-275.

Gergen, K.J. (1994). Reality and relationships, soundings in social construction. Cambridge: Harvard University Press.

Gergen, K. J. (1996). Social psychology as social construction: The emerging vision. In (Eds. C. McGarty and A. Haslam) The Message of Social Psychology: Perspectives on Mind in Society. Oxford: Blackwell. Pp: 113-128

Greenwood, R., Suddaby, R. and Hinings, C.,R., (2002). Theorizing Change: The Role of Professional Associations in the Transformation of Institutional Fields. Academy of Management Journal, 45, 58-80.

Guarnieri, M. (1992). Landmarks in the history of safety. Journal of Safety Research, 23, 151-158.

Gundry, L. K., and Rousseau, D. M. (1994). Critical incidents in communicating culture to newcomers: The meaning is the message. Human Relations 47(9) 1063-1088.

Haddon, Jr., W. (1980). Advances in the epidemiology of injuries as a basis for public policy. Public Health Reports, 95, 5, 411-421.

Hardy, C., and Maguire, S. (2010). Discourse, field-configuring evens, and change in organizations and institutional fields: Narratives of DDT and the Stockholm convention. Academy of Management Journal, 53 (6): 1365-1392

Harris, J. E. (1977). The internal organization of hospitals: Some economic implications. Bell Journal of Economics, 8 (2): 467-482

Hunter, K. M. (1991) Doctor's stories: The narrative structure of medical knowledge. Princeton, CA: Princeton University Press.

Iedema, R. (2001) Resemiotization. Semiotica 137-1/4: 23-39.

Jha, A. K., Prasopa-Plaizier, N., Larizgoitia, I. and Bates, D. W. (2010). Patient safety research: An overview of the global evidence. Quality and Safety in Health Care, 19 (1): 42-47.

Jepperson, R. L. (1991). Institutions, institutional effects, and institutionalism. In W. W. Powell \& P. J. DiMaggio, (Eds.), The new institutionalism in organizational analysis, pp. 143-163. University of Chicago Press: Chicago.

Kantor, J. R. (1929). An outline of social psychology. Chicago: Follett Publishing. Retrieved July 2012 from http://www.brocku.ca/MeadProject/Kantor/1929/1929 toc.html

Kendall, G., and Wickham, G. (1999). Using Foucault's methods. London, UK: Sage. 
Kerosuo, H., Kajamaa, A. and Engeström, Y. (2006). Organizational learning rememberedtraces of change in narratives, documents and material artefacts. Presentation to OLKC 2006 Conference at the University of Warwick, Coventry on 20th - 22nd March 2006. Retrieved July 2012 from http://www2.warwick.ac.uk/fac/soc/wbs/conf/olkc/archive/olkc1/papers/289_kerosuo. pdf

Knorr-Cetina, K. (1997) 'Sociality with Objects. Social Relation in Postsocial Knowledge Societies', Theory, Culture and Society 14(4): 1-31.

Kohn, L.T., Corrigan, J, M., and Donaldson, M. S. (Eds.) (1999/2000). To err is human: Building a safer health system. Washington, DC: Committee on Quality of Health Care in America, Institute of Medicine, National Academy Press. Retrieved from http://www.nap.edu/catalog.php?record_id=9728

Lampel, J., and Meyer, A. D. (2008). Field-configuring events as structuring mechanisms: How conferences, ceremonies, and trade shows constitute new technologies, industries, and markets. Journal of Management Studies, 45: 1025-1035.

Latour, B. (1991). Technology is society made durable, in J. Law (ed.) A Sociology of Monsters: Essays on Power, Technology and Domination, pp. 103-32. Sociological Review Monograph 38.

Latour, B. (1992). Where are the missing masses? The Sociology of a Few Mundane Artefacts, in W. Bijker and J. Law (eds) Shaping Technology/Building Society. Studies in Sociotechnical Change, pp. 225-64. Cambridge, MA: MIT Press.

Latour, B. (2005). Reassembling the Social: An Introduction to Actor-Network-Theory. Oxford: Oxford University Press.

Lawrence, T.B. and Suddaby, R. (2006). Institutions and institutional work. In S. R. Clegg, C. Hardy, T. B. Lawrence \& W. R. Nord (Eds.), Handbook of organization studies. 2nd

edition, 215-254. London: Sage.

Leape, L. L., Berwick, D., Clancy, C., Conway, J., Gluck, P., Guest, J., Lawrence, D., Morath, J., O’Leary, D., O’Neill, P., Pinakiewicz, D, and Isaac, T. (2009).

Transforming healthcare: A safety imperative. Quality of Safety and Healthcare, 18: 424-428

Leape, L. L., Brennan, T. A., Laird, N. M., Lawthers, A.G, Localio, A.R., Barnes, B. A., Hebert, L., Newhouse, J. P., Weiler, P. C., and Hiatt, H. (1991). The nature of adverse events in hospitalized patients: Results of the Harvard Medical Practice Study II. New England Journal of Medicine, 324(6):377-384

Leape L. L., Lawthers, A. G., Brennan, T. A. and Johnson, W. G. (1993). Preventing medical injury. Quality Review Bulletin. 8:144-149.

Leape, L. L. (1994). Error in medicine. Journal of the American Medical Association. 272(23):1851-1857

Lewis, B. L. and Alexander, J. (1986). A taxonomic analysis of multihospital system. Health Services Research 21, 1, 29-56.

Lind, R.W., (1980). Attention and the Aesthetic Object. The Journal of Aesthetics and Art Criticism, 39 (2), 131-142

Making Health Care Safer II: An Updated Critical Analysis of the Evidence for Patient Safety Practices (2013). Evidence Reports/Technology Assessments, No. 211. Rockville (MD): Agency for Healthcare Research and Quality (US). Report No.: 13-E001-EF. Retrieved April 2014 from http://www.ncbi.nlm.nih.gov/books/NBK133363/

Millenson, M. L. (2002). Pushing the profession: How the news media turned patient safety into a priority. Quality and Safety in Health Care, 11:57-63 
Mohr, J. C. (2000). American medical malpractice litigation in historical perspective. Journal of the American Medical Association, 283(13):1731-1737

National Patient Safety Foundation (1995). http://www.npsf.org/

Norman, D., A. (1991): Cognitive artefacts. In: Carroll, John M. (ed.). Designing interaction: Psychology at the Human-Computer interface. Cambridge, UK: Cambridge University Press. pp. 17-38.

Olson, D. R. (1994). The world on paper: The conceptual and cognitive implications of writing and reading. Cambridge: Cambridge University Press.

Parker, I. (1994). Reflexive research and the grounding of analysis: Social psychology and the psy-complex. Journal of Community and Applied Psychology, 4, 239-252.

Pentland, B.T., (1999). Building process theory with narrative: From description to explanation. Academy of Management Review, 24 (4), 711-714.

Phillips, N., Lawrence, T. B., and Hardy, C. (2004). Discourse and institutions. Academy of Management Review, 29, 635-652.

Prior, L. (2003) Using documents in social research. Sage Publications Ltd.

Ricoeur, P. (1971). The model of the text: meaningful action considered as a text. Social Research, 38 (3), 529-562.

Ricoeur, P. (1981) Hermeneutics and the human sciences: Essays on language, action and interpretation. (Edited and translated by H. P. Rickman.) Cambridge: Cambridge University Press.

Runyan, C. W. (2003). Introduction: Back to the future-revisiting Haddon's conceptualization of injury epidemiology and prevention. Epidemiologic Reviews, 25: 60-64.

Schiffer, M.B. (1999). The material life of human beings: Artefacts, behavior, and communication. Routledge, London.

Schimmell, E. M. (2003/1964). (Reprinted) The hazards of hospitalization. Quality and Safety in Healthcare, 12: 58-64.

Scott, W.R. (2007). Institutions and organizations: Ideas and interests. Thousand Oaks, CA: Sage Publications.

Shanahan, E.,A., Jones, M.,D., and McBeth, M.,K., (2011). Policy narratives and policy processes. The Policy Studies Journal, 39 (3), 535-561.

Simon, H. A. (1976) Administrative Behavior. A Study of Decision-making Process in Administrative Organization, 3rd edn. London: Free Press.

Stevenson, W. B. and Greenberg, D. N. (1998). The formal analysis of narratives of organizational change. Journal of Management, 24, 6: 741-762.

Van Dijk, T. A. (1993). Principles of critical discourse analysis. Discourse and Society, 4: 249-283.

Swain, M., \& Lapkin, S. (2002). Talking it through: Two French immersion learners' response to reformulation. International Journal of Educational Research, 37(3-4), 285-304.

Vygotsky, L. (1978). Interaction between learning and development. Mind and society, (Trans. M. Cole). (pp. 79-91). Cambridge, MA: Harvard University Press.

Vygotsky, L. S., (1979). Consciousness as a problem in the psychology of behavior. Soviet Psychology, 17, 3-35. Retrieved Jan 2014 from https://www.marxists.org/archive/vygotsky/works/1925/consciousness.htm

Vygotsky, L.S. (1981) The instrumental method in psychology. In J.V. Wertsch, (Ed.), The concept of activity in Soviet psychology. Armonk, NY: M.E. Sharpe, pp. 134-143.

Vygotsky, L. (1934/1986). Thought and language. Cambridge, MA: MIT Press. 
Vygotsky, L.S., (1987). Thinking and speech (U. Minick, Ed. and Trans.). New York: Plenum.

Wartofsky, M. W. (1973). Models: Representation and scientific understanding. Dordrecht, The Netherlands: Reidel.

Wartofsky, M. (1987) 'Epistemology Historicized', in A. Shimony and D. Nails (eds) Naturalistic Epistemology, pp. 357-74. Dordrecht: Reidel.

Wertsch, J .V. (1998). Mind as action. Oxford, UK: Oxford University Press.

White, H. (1981). The value of narrativity in the representation of reality. In W. J. T. Mitchell (ed.), On Narrative: 1-23. London: The University of Chicago Press.

Willig, C. (1990). Introducing qualitative research in psychology. Maidenhead, UK: Open University Press.

Woods, D.W.,(1998). Designs are Hypotheses about How Artifacts Shape Cognition and

Collaboration Ergonomics, 41, 168-173.

Woodward, H. I., Mytton, O. T., Lemer, C., Yardley, I. E., Ellis, B. M., Rutter, P. D., Greaves, F. E. C. ...Wu, A. W. (2010). What have we learned about interventions to reduce medical errors? Annual Review of Public Health 31(1): 479-497. 